PREPARED FOR THE U.S. DEPARTMENT OF ENERGY, UNDER CONTRACT DE-AC02-76-CHO-3073

PPPL-2870

PPPL-2870

- UC-427

TRANSPORT NEAR STOCHASTIC THRESHOLD

BY

R.B. WHITE, J.M. RAX, AND Y. WU

DECEMBER, 1992
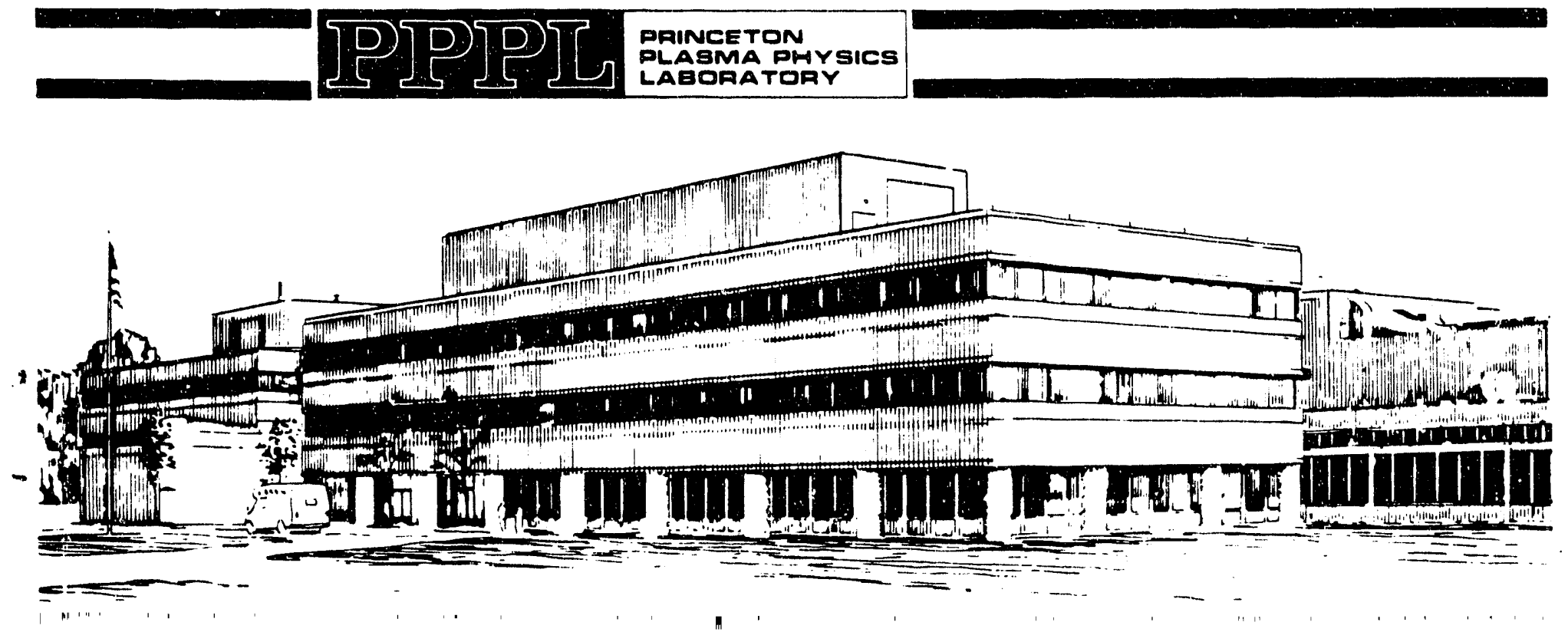


\section{NOTICE}

This report was prepared as an account of work sponsored by an agency of the United States Government. Neither the United States Government nor any agency thereof, nor any of their employees, makes any warranty, express or implied, or assumes any legal liability or responsibility for the accuracy, completeness, or usefulness of any information, apparatus, product, or process disclosed, or represents that its use would not infringe privately owned rights. Reference herein to any specific commercial produce, process, or service by trade name, trademark, manufacturer, or otherwise, does not necessarily constitute or imply its endorsement, recommendation, or favoring by the United States Government or any agency thereof. The views and opinions of authors expressed herein do not necessarily state or reflect those of the I'nited States Government or any agency thereof.

\section{NOTICE}

This report has been reproduced from the best available copy.

Available in paper copy and microfiche.

Number of pages in this report: 16

DOE and DOE contractors can obtain copies of this report from:

Office of Scientific and Technical Information

P.O. Box 62

Oak Ridge, TN 37831 ;

(615) $576-8401$.

This report is publicly available from the:

National Technical Information Service

Department of Commerce

5285 Port Royal Road

Springfield, Virginia 22161

(703) $487-4650$ 
PPPL- -2870

DE93 005728

\title{
TRANSPORT NEAR STOCHASTIC THRESHOLD
}

\author{
R.B. White, J.M. Rax, Yanlin Wu \\ Princeton Plasma Physics Laboratory, Princeton University, \\ P.O. Box 451, Princeton, New Jersey. 08543
}

\begin{abstract}
Transport in a magnetic field configuration near stochastic threshold is investigated. The waiting time distribution near magnetic islands, and the size distribution of these islands are identified as the two fundamental functions which determine both the short time subdiffusive behavior, and the regular diffusive regime. These time and length distributions are studied, the mean square displacement is expressed in terms of these functions, and the result is compared to direct numerical simulation.
\end{abstract}


A three dimensional toroidal "gnetic field is a Hamiltonian system, and the existence of magnetic surfaces in an axisymmetric configuration is a consequence of the KolmogorovArnold-Möser (K.A.M) stability theorem. Chirikov overlap of small resonant magnetic field perturbations can lead to the onset of chaotic field line diffusion [1]. This deconfinement mechanism is a candidate to explain the anomalous confinement properties of tokamak discharges $[2,3]$.

In a previous work we reported a numerical confirmation of the Rechester-Rosenbluth (RR) regime well above stochastic threshold [4]. In the present work we address the critical issue of transport near stochastic threshold, a probable state of a braided magnetic field in tokamaks.

We find that transport in this state can be understood in terms of two basic functions; the waiting time distribution around magnetic islands and the size distribution of these islands. We study these distribution functions and calculate the mean square displacement. Both the initial subdiffusive behavior and the final diffusive motion agree with direct numerical simulation.

Near threshold the islands have two effects on transport. First, a geometrical effect: the volume occupied by the islands does not contribute to transport [5]. Second, a dynamical effect: an orbit spends a lons time wandering around each island before crossing the stochastic sea and striking the next island. This sequence determines the behavior and magnitude of transport near threshold, the geometrical structure of phase space entering the associated waiting time distribution through the island size distribution.

The transport of a scalar can always be decomposed as a set step/pause/step/pause/step... To complete this structural reduction of the random walk near threshold we must introduce the waiting time distribution at the pause $\psi(\mathrm{t}) \mathrm{dt}=($ Probability to wait a time $t)$ and the step size distribution $\phi(\mathrm{s}) \mathrm{d} s=($ Probability of a step size $s)$.

We are interested in the mean square displacement $\left\langle x^{2}(t)\right\rangle$. Given an $N$ step walk we can write: 


$$
\left\{\begin{array}{l}
\left\langle\mathrm{x}^{2}\right\rangle=\left\langle\left[\sum_{1}^{N} s_{\mathrm{i}}\right]^{2}\right\rangle=N \int_{0}^{s_{o}} s^{2} \phi(s) d s \\
\langle\mathrm{t}\rangle=\left\langle\sum_{1}^{N} \mathrm{t}_{\mathrm{i}}\right\rangle=N \int_{0}^{\mathrm{t}_{0}} \mathrm{t} \psi(\mathrm{t}) \mathrm{dt}
\end{array}\right.
$$

To express the mean square displacement as a function of the time we have to eliminate $\mathrm{N}$ from these equations. However for fixed $\mathrm{N}$, the particles do not completely explore the distribution of step sizes and waiting times. Thus rather than taking $s_{0}=t_{0}=+\infty$, we introduce two cut off points which are in fact $N$ dependent: $t_{\mathrm{o}}=\mathrm{t}_{\mathrm{m}}(\mathrm{N})$ and $\mathrm{s}_{\mathrm{o}}=\mathrm{s}_{\mathrm{m}}(\mathrm{N})$. This regularization gives the same result as a renormalization group procedure. When these integrals are well behaved, we get normal diffusion with $D_{\text {eff }}=\int s^{2} \phi(s) d s / 2 \int t \psi(t) d t$. But in the generic case the regularization, depending on the behavior of $\phi$ and $\psi$ at large argument, gives rise to the occurrence of anomalous behavior [6] of the type

$$
\left\langle\mathrm{x}^{2}(\mathrm{t})>\sim \mathrm{t}^{\alpha}, \quad \quad<\mathrm{x}^{2}(\mathrm{t})>\sim \log ^{\beta}[\mathrm{t}] .\right.
$$

The exponents $\alpha$ and $\beta$, characterizing the random walk, can be larger or smaller than one, with . anomalously long trapping time or ballistic flights often the cause of this subdiffusive or hyperdiffusive transport. The occurrence of logarithmic behavior is also often due to trapping. The case $\beta=4$ has been found by Sinai for diffusion in a random one dimensional potential [7].

In reference [4] we investigated transport above stochastic threshold using a Chirikov-Taylor model. In this model a Lagrangian representation of heat flow along and across the magnetic field is achieved by adding a random reversal of the velocity $\mathrm{v}$ correlated with a cross field displacement of gyroradius $\rho$. The Poincaré section of such a dynamics for $v_{t}=1$ is:

$$
\left\{\begin{array}{l}
z_{t+1}=z_{t}+v_{t} \\
y_{t+1}=y_{t}+x_{t+1} \\
x_{t+1}=x_{t}+\varepsilon \sin \left[y_{t}\right]+\rho_{t}
\end{array}\right.
$$

and for $v_{t}=-1$ the second and third equations must be inverted so that for $\rho_{t}=0$ a particle retraces its path back along the field line. The sign of $v_{t}$ for each particle is changed each time 
step with probability $\mathrm{P}$ producing diffusive motion in $\mathrm{z}$. A collisional displacement $\rho_{1}$ of magnitude $\rho$ and random sign is given to $x$ on those time steps that $v_{t}$ changes sign.

The Lyapounov length is evaluated with the usual algorithm [8]. The parallel mean free path is $\lambda_{C}=(1-\mathrm{P}) / \mathrm{P}$, and the parallel and perpendicular diffusions are $\chi_{\|}=(1-\mathrm{P}) / 2 \mathrm{P}$ and $\chi_{\perp}=\rho^{2} \mathrm{P} / 2$.

Near threshold we observe subdiffusive behavior of logarithmic type followed by diffusive motion. The numerical diffusion coefficient agrees with the Rechester-Rosenbluth value, $D_{R R}$. provided that one uses the numerical magnetic diffusion coefficient. This value, determined by the anomalous waiting time of a field line around the islands and the island size distribution, is very different from the quasilinear value. It is remarkable that the analysis leading to $D_{R R}$ is valid even though the diffusion of the magnetic field lines proceeds through a process quite unlike that occurring well above threshold.

For example, for $\varepsilon=1.1, P=.8, \rho=10^{-8}$ we find subdiffusive behavior with $\beta \approx 1$ for $t<$ $5 \times 10^{6}$. For very large $t$ we find $\left\langle x^{2}(t)\right\rangle=2 D_{R R} t$ with $D_{R R} \approx 1.5 \times 10^{-7}$, whereas the quasilinear estimate gives $D_{R R} \approx 10^{-3}$. In the present work we will use these parameter values. to illustrate the results. A more complete discussion including transitions to other domains will be presented in a future publication.

To calculate the distribution of island size we proceed as follows. Introduce a grid, and calculate the extent of the stochastic sea by initially setting the function $n(i, j)=1$ everywhere and then following a single long orbit in the stochastic sea, setting $n(i, j)=0$ for each grid square visited. Then sequentially label connected sets of island points and finally join the islands at the edges of the domain in accordance with topological identification on the torus. Then by counting the number of points to determine the area of each island, a complete catalogue of islands can be made, each with its associated area and perimeter, from the island of maximum size $s_{0}$ down to islands of the grid size. Sample results are shown in Fig. 1 for $\varepsilon=1.1$.

Using continuum notation, the expression for the total area of all islands with size greater than $s$ as a function of the density of islands of size $s, D(s)$, is 


$$
A(s)=\int_{s}^{s_{o}} s^{2} D(s) d s
$$

The spectrum of island size, shown in Fig. 2, has two regimes. For small islands the distribution of the islands is a fat fractal [9], with $A(s)$ being given by

$$
A(s)=A(0)-c s^{p}
$$

and for $\varepsilon=1.1, \mathrm{~A}(0) \approx 17, \mathrm{c} \approx 1.3, \mathrm{p} \approx 0.6$. For $\mathrm{s} \leq \mathrm{s}_{0}$ the scaling is quite different, and we obtain

$$
\mathrm{A}(\mathrm{s})=\mathrm{b} \mathrm{s}^{-\mathrm{a}}
$$

with $a \approx 0.2, b \approx 12$. From Eq. (4) we find, in this domain, $D(s)=a b s s^{-(3+a)}$. We refer to this scaling regime as the dynamical range, as we will see that it determines the transport in the medium. Equations (5) and (6) capture all the statistical geometrical properties of the phase space near threshold.

By following single particle orbits we find that long periods of time are spent circling the . periphery of the largest islands, according to the sequence capture/trapped/escape. Near threshold, the dominant contribution to the time spent in any orbit comes from this trapping near the largest island.

To quantify this process we measure the trapping time as a function of the island size, using initial conditions with the particle located within the stochastic sea, but close to an island. We choose the initial point to be within one grid spacing of the island. The minimum distance to the island perimeter is then monitored as a function of time. Figure 3 depicts a typical realization of this process, showing a plot of this distance versus time. (This plot shows a short-time average of the distance, so does not display the fine scale bursting and intermittency which is present.) The particle spends a long time stuck near the surface of the island, where the level of stochasticity is only slightly above threshold. However once it has diffused to a point well inside the stochastic sea, the rate of escape from the island increases rapidly. 
By exploring many initial points distributed about the perimeter of the islands a well defined mean trapping time is found. We have numerically determined this trapping time for four of the largest islands. These correspond to the period one island (a in Fig. 1), the period two islands (b in Fig. 1) the period three islands ( $c$ in Fig. 1), and the period five islands (d in Fig. 1). Note that for islands with period greater than one the perimeter must be taken as the union of points in the perimeters of all islands in the chain. The trapping times obtained in this manner are shown in Fig. 4. The mean trapping time, $\tau$, depends exponentially on the island perimeter,

$$
\tau(s)=\tau_{0} e^{s / L}
$$

where for these parameters $\tau_{0} \approx 5 \times 10^{5}, \mathrm{~L} \approx 0.5$ (the occurrence of exponential trapping time is quite common in the theory of transport in disordered media). This result is clearly incorrect for $s<<$, as it indicates that infinitesimal islands have a trapping time independent of their size. For lack of a better procedure we will truncate $\tau(\mathrm{s})$ at $\delta \approx 1 \mathrm{~L}$. Results are insensitive to this value as long as it is not taken to be much smaller than this.

The dependence of $\tau_{0}$ and $L$ on $\varepsilon, \rho$ and $P$ will be discussed in a future publication. However, we note that the same dependence, Eq. (7), exists for $P=0, \rho=0$, i.e., for magnetic field line diffusion, with $\tau_{0} \approx 50, L \approx 0.5$. In this case $\tau(\mathrm{s})$ gives the length of the field line remaining close to the island before escaping. The collisional trapping time is shorter than the time required to diffuse this distance with $\chi_{||}$, i.e., particles do not escape the islands simply by diffusing along the escaping field line, $\tau_{0}$ is shortened by the cross field diffusion. We conclude that for small $\rho, L$ is mostly determined by the geometrical phase space structure, i.e., depends only on $\varepsilon$, but $\tau_{0}$ depends on both $P$ and $\rho$. Clearly these dependencies determine the variation of the transport with energy and mass. The domain of validity of Eq. (7) will be discussed in a future publication. In all these determinations, but particularly for magnetic field line diffusion, the numerical experiment is complicated by the existence of nearby undetected islands (smaller than the grid size), the interiors of which are obviously not allowed as initial conditions. 
Using Eqs. (1), (6), and (7) we can calculate the mean squared displacement. Diffusion consists of steps with size given by the linear dimension of an island, and pauses while the particle is attached to an island (not all the pauses occur around islands or all the steps between islands, but for a statistically significant set of realizations, the relevant sums are dominated by these processes). To evaluate $\phi(s)$ consider a random path through the medium. The probability of intersecting an island of size $s$ and thus the distribution of island sizes encountered along the trajectory is $\phi(s)=s \mathrm{D}(\mathrm{s})$. The distribution of trapping times is also related to the distribution of the islands through

$$
\psi(t)=\int \delta[\tau(s)-t] \phi(s) d s .
$$

To find the cut off points $s_{m}$ and $t_{m}$ giving the regularization consider a trajectory having encountered $\mathrm{N}$ islands according to the probability $\phi$. The limit $\mathrm{s}_{\mathrm{m}}$, and hence the large scale islands not visited is given by the expression

$$
\int_{s_{m}(N)}^{s_{o}} \phi(s) d s=\frac{1}{N} .
$$

Substituting this expression into Eq. (1) gives the mean squared displacement as an implicit function of time

$$
<x^{2}>=\frac{\int_{\delta}^{s_{m}} s^{2} \phi(s) d s}{\int_{s_{m}}^{s_{0}} \phi(s) d s}, \quad<t>=\tau_{0} \frac{\int_{\delta}^{s_{m}} e^{s / L} \phi(s) d s}{\int_{s_{m}}^{s_{0}} \phi(s) d s} .
$$

Note $\left\langle\mathrm{x}^{2}\right\rangle$ is independent of the cutoff $\delta$, but $<\mathrm{t}>$ diverges if $\delta \rightarrow 0$, reflecting the incorrect behavior of Eq. (6) for small s. These expressions are independent of the normalization of $\phi$. The subdiffusive behavior can be obtained by evaluating the leading contributions to these integrals. For $s_{m}<s_{0}$ this dominant scaling is $\left\langle x^{2}\right\rangle \approx \log ^{a+1}[t]$. Using the measured value $a=0.2$ this result agrees reasonably with the observed subdiffusive behavior, which lasts until $t=$ $5 \times 10^{6}$, i.e., from Fig. 4 , until all but the single largest island have been explored. 
For times long enough that the entire island spectrum has been sampled, there is diffusive motion with

$$
\left.D_{\text {eff }}=\int_{\delta}^{\text {so }} s^{2} \phi(s) d s\right) /\left[2 \tau_{0} \int_{\delta}^{\text {so }} e^{s / L} \phi(s) d s\right] .
$$

Using Eqs. (5) and (6), and evaluating these integrals we find agreement with the direct numerical simulations within a factor of 2 both for the collisional case and for field line diffusion. Further above threshold $\left\langle\mathrm{x}^{2}\right\rangle$ and $\langle\mathrm{t}\rangle$ must include contributions from the stochastic sea, which finally dominate well above threshold, leading to the usual quasilinear expression for $D_{R R}$ and to the quasilinear value $\varepsilon^{2} / 4$ for the magnetic field lines.

In conclusion, we have investigated transport in a stochastic magnetic field near stochastic threshold using the Chirikov-Taylor map. We have identified the statistical geometrical properties of the underlying phase space, $\phi(s)$, and the dynamical properties of the islands, $\tau(s)$, as the building blocks of the macroscopic transport process. Moreover Eqs. (10) and (11) give the mean square displacement both in the early subdiffusive regime and the long time diffusive regime.

Slightly above stochastic threshold short time propagation is subdiffusive, with $\left\langle x^{2}\right\rangle \approx \log ^{\beta}(t)$. The exponent of the log is determined by the spectrum of islands in the stochastic sea. For sufficiently long times transport is diffusive. The Rechester Rosenbluth formula is correct provided one uses the effective magnetic diffusion given by Eq. (11) rather than the quasilinear value. The island size spectrum and the trapping time determine the value of this near-threshold diffusion constant, which can be orders of magnitude smaller than the quasilinear value both in the collisional and collisionless case.

This work was supported by the U.S. Department of Energy under contract number DE-AC0276-CHO3073. 


\section{References}

[1] M.N. Rosenbluth, R.Z. Sagdeev, J.B. Taylor, and G.M. Zaslavski, Nucl. Fusion 6, 415. (1966). N.N. Filonenko, R.Z. Sagdeev, and G.M. Zaslavski, Nuc. Fus. 7, 253 (1967).

[2] A.B. Rechester, and M.N. Rosenbluth, Phys. Rev. Lett. 40, 38 (1978).

[3] T.H. Stix, Nucl. Fusion 18, 354 (1978).

[4] J. M. Rax and R. B. White, Phys. Rev. Lett . 68, 1523 (1992).

[5] M. N. Bussac and L. Zuppiroli, Phys. Lett. A 161, 365 (1992)

[6] W. Young, A. Pumir, and Y. Pomeau, Phys. Fluids A 1, 462 (1989). G.M. Zaslavski, R.Z. Sagdeev, D.K. Chaikovski, and A.A. Chernikov, Sov. Phys. JETP 68, 995 (1989). Y. Gefen, A. Aharony, and S. Alexander Phys. Rev. Lett. 50, 77 (1983). B. O'Shaughnessy and I. Procaccia Phys. Rev. Lett. 54, 455 (1985).

[7] Ya. Sinai, in Proceedings of the Berlin Conference on Mathematical Problems in Theoretical Physics, R. Schrader, R. Seiler, and D. A. Uhlenbrock ed. (Springer, Berlin, 1982).

[8] A.B. Rechester, M.N. Rosenbluth and R.B.White Phys. Rev. Lett. 42, 1247 (1978).

[9] D. Umberger and J. Farmer, Phys. Rev. Lett. 55, 581 (1985). 


\section{Figure Captions}

Fig. 1: Island perimeters found using a grid mesh of $1000 \times 1000, \varepsilon=1.1$.

Fig. 2: The distribution of island size for $\varepsilon=1.1$. Note the occurrence of two scaling regimes. The letters refer to the islands depicted on Fig. 1.

Fig. 3: Distance from island perimeter for island $\mathrm{c}$ in Fig. 1, as a function of time.

Fig. 4: Trapping time as a function of island size s. The points were obtained using initial conditions next to the islands, a, b, c, and d in Fig. 1. The vertical bars indicate the width of the distribution about the lear. 


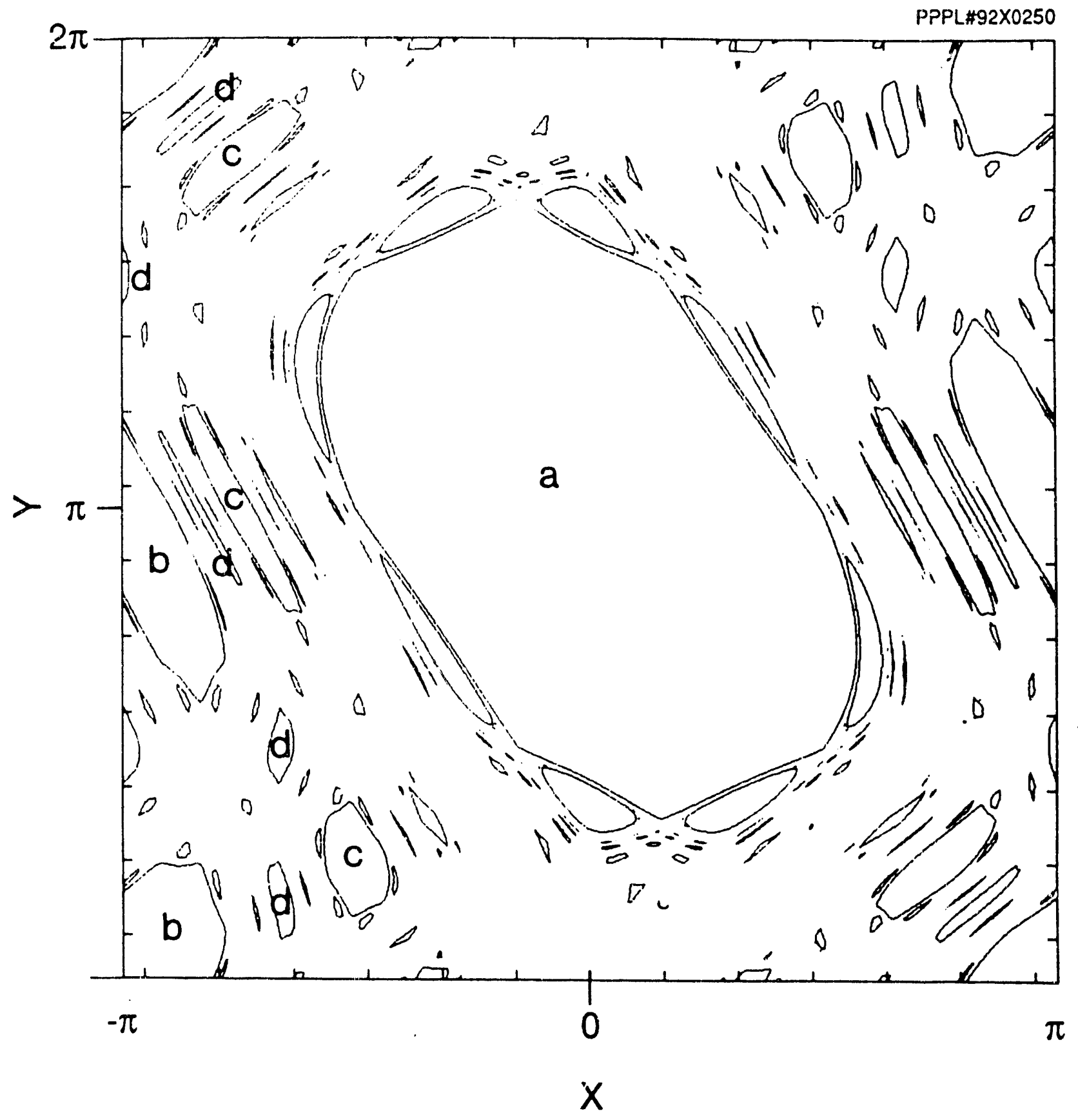

FIG. 1 


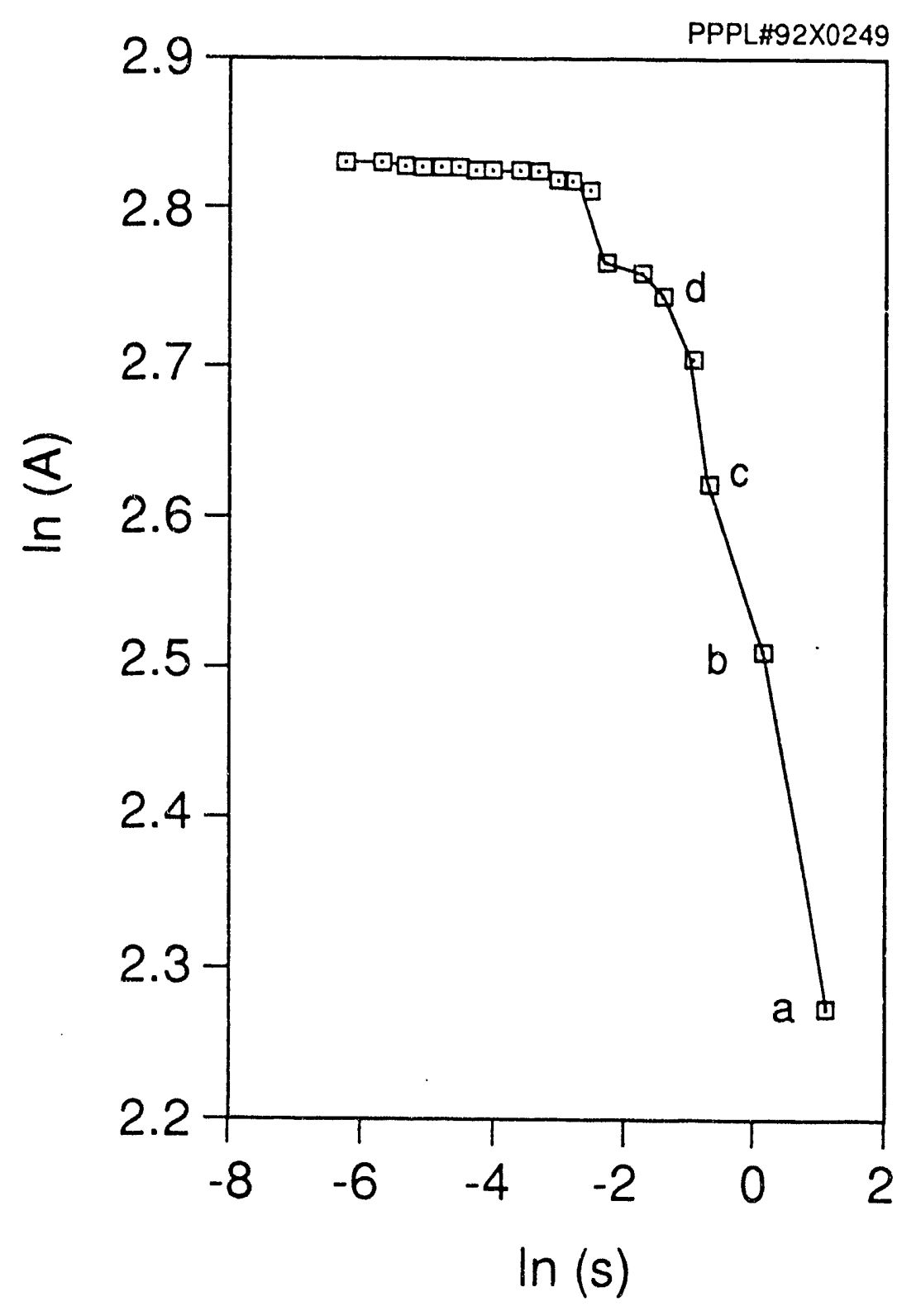

FIG. 2 
PPPL\#92T0009

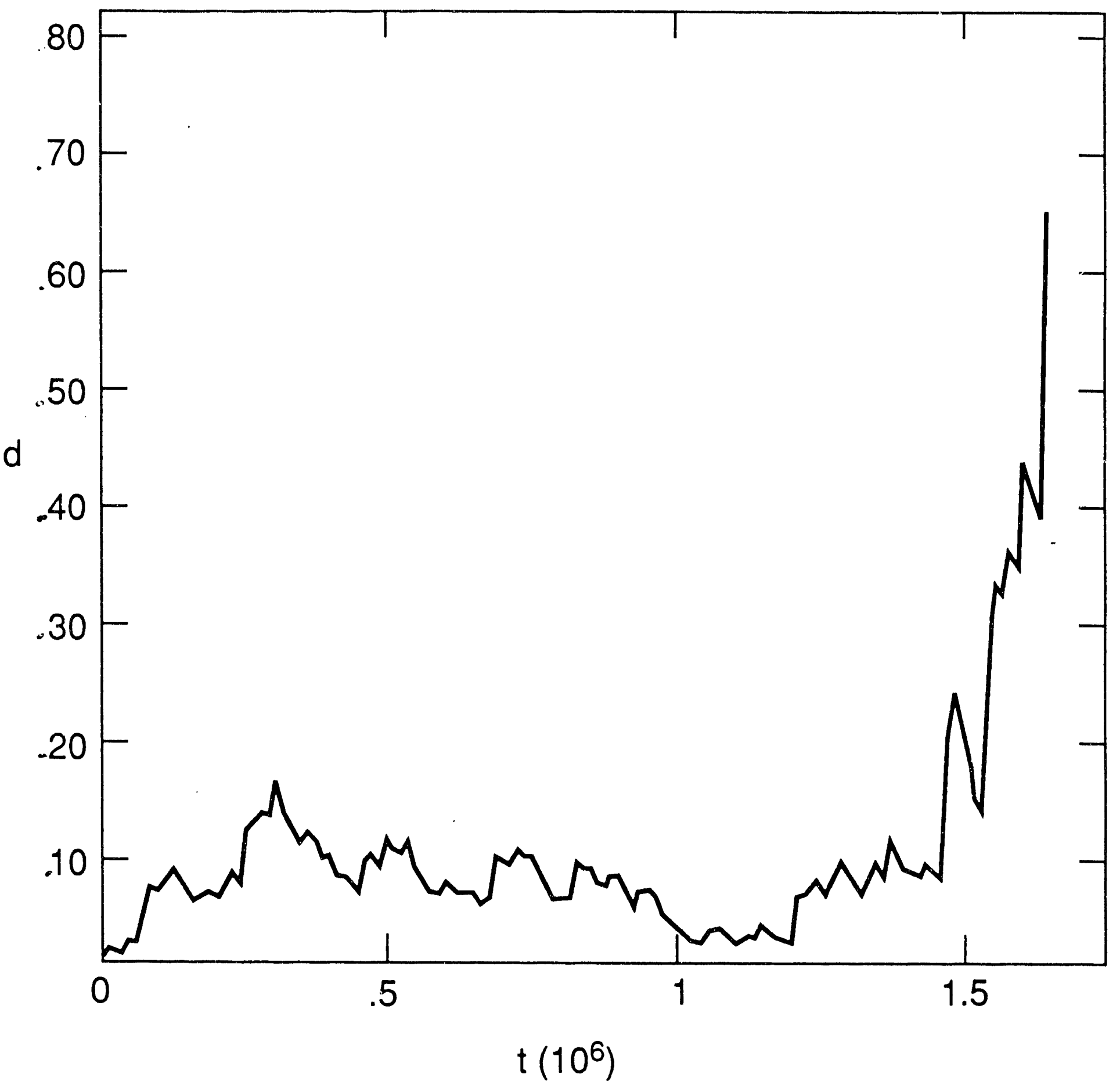

FIG. 3 


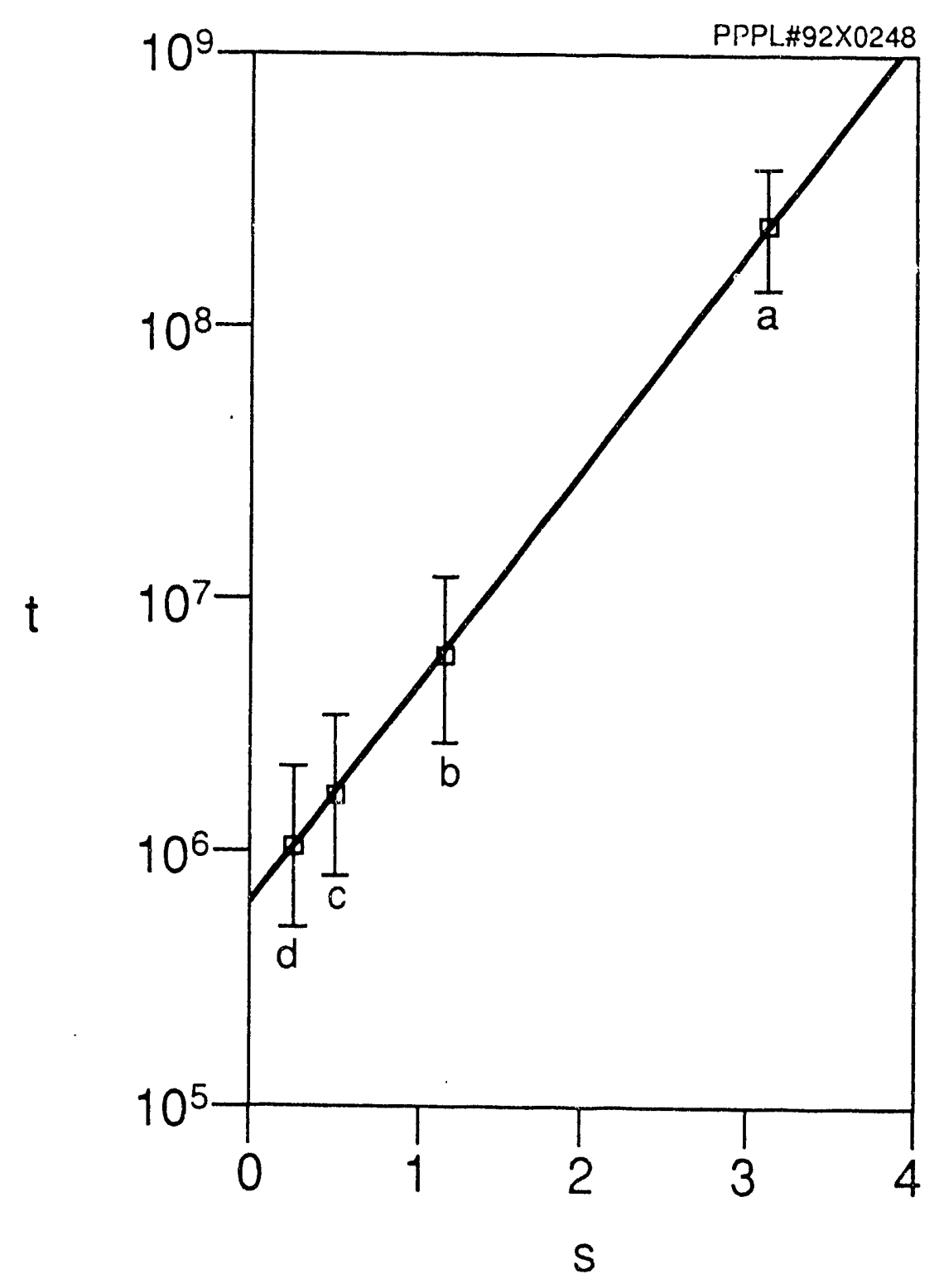

EIG. 4 
Dr. F. Paoloni, Univ. of Wollongong, AUSTRALIA

Prof. M.H. Brennan, Univ. of Sydney, AUSTRALIA

Plasma Research La's., Australian Nat. Univ., AUSTRALIA

Prof. I.R. Jones, Flinders Univ, AUSTRALIA

Prof. F. Cap, Inst. for Theoretical Physics, AUSTRIA

Prof. M. Heindler, Institut tür Theoretische Physik, AUSTRIA

Prof. M. Goossens, Astronomisch InstituUt, BELGIUM

Ecole Royale Militaire, Lab. de Phy. Plasmas, BELGIUM

Commission-European, DG. XII-Fusion Prog., BELGIUM

Prof. R. Bouciqué, Rijksuniversiteit Gent, BELGIUM

Dr. P.H. Sakanaka, Instituto Fisica, BRAZIL

Instituto Nacional De Pesquisas Espaciais-INPE, BRAZIL

Documents Office, Atomic Energy of Canada Lid., CANADA

Dr. M.P. Bachynski, MPB Technologies, Inc., CANADA

Dr. H.M. Skarsgard, Univ. of Saskatchewan, CANADA

Prof. J. Toichmann, Univ. of Montreal, CANADA

Prof. S.R. Sroenivasan, Univ. of Calgary, CANADA

Prof. T.W. Johnston, INRS-Energie, CANADA

Dr. R. Bolton, Centre canadien de fusion magnétique, CANADA

Dr. C.R. James., Univ. of Alberta, CANADA

Dr. P. Lukác, Komenského Universzita, CZECHO-SLOVAKIA

The Librarian, Culham Laboratory, ENGLAND

Library, R61, Ruthertord Appleton Laboratory, ENGLAND

Mrs. S.A. Hutchinson, JET Library, ENGLAND

Dr. S.C. Shama, Univ. of South Pacific, FIJI ISLANDS

P. Măhơnen, Univ. of Helsinki, FINLAND

Prof. M.N. Bussac, Ecole Polyrochnique, FRANCE

C. Mouttet, Lab. de Physique des Milieux lonisés, FRANCE

J. Radet, CEN/CADARACHE - Bat 506, FRANCE

Prof. E. Economou, Univ. of Crete, GREECE

Ms. C. Rinni, Univ. of loarmina, GREECE

Dr. T. Mual, Acadomy Bibliographic Ser., HONG KONG

Preprint Library, Hungarian Academy of Sci., HUNGARY

Dr. B. DasGupta, Saha Inst. of Nuclear Physics, INDIA

Dr. P. Kaw, Inst. for Plasma Research, INDIA

Dr. P. Rosenau, Israel inst. of Technology, ISPAEL

Librarian, International Center for Theo Physics, ITALY

Miss C. De Palo, Associazione EURATOM-ENEA , ITALY

Dr. G. Grosso, Istituto di Fisica del Plasma, ITALY

Prof. G. Rostangni, Istituto Gas lonizzati Dol Cnr, ITALY

Dr. H. Yamato, Toshiba Res a Devel Center, JAPAN
Prof. I. Kawakami, Hiroshima Univ., JAPAN

Prof. K. Nishikawa, Hiroshima Univ., JAPAN

Director, Japan Atomic Energy Research Inst., JAPAN

Prof. S. Itoh, Kyushu Univ., JAPAN

Research Info. Ctr., National Instit. for Fusion Science, JAPAN

Prof. S. Tanaka, Kyoto Univ., JAPAN

Library, Kyoto Univ., JAPAN

Prof. N. Inowe, Univ. of Tokyo, JAPAN

Secretary, Plasma Section, Electrotochnical Lab., JAPAN

S. Mori, Tectnical Advisor, JAERI, JAPAN

Dr. O. Miteraj, Kumamoto Inst. of Technology, JAPAN

J. Hyeon-Sook, Korea Atomic Energy Research inst., KOREA

D.I. Choi, The Korea Adv. Inst. of Sai. \& Tech., KOREA

Prof. B.S. Liley, Univ. of Waikato, NEW ZEALAND

Inst of Physics, Chinese Acad Sci PEOPLE'S REP. OF CHINA

Library, Inst. of Plasma Physics, PEOPLE'S REP. OF CHINA

Tsinghua Univ. Library, PEOPLE'S REPUBLIC OF CHINA

2. L. S.W. Inst Physics, PEOPLE'S REPUBLIC OF CHINA

Prof. J.A.C. Cabral, Instituto Superior Tecnico, PORTUGAL

Dr. O. Petrus, AL I CUZA Univ., ROMANIA

Dr. J. de Villiers, Fusion Studies, AEC, S. AFRICA

Prot. M.A. Hellborg, Univ. of Natal, S. AFRICA

Prof. D.E. Kim, Pohang Inst. of Sci. \& Tech., SO. KOREA

Prof. C.I.E.M.A.T, Fusion Division Library, SPAIN

Dr. L. Stonflo, Univ. of UMEA, SWEDEN

Library, Royad Inst. of Technology, SWEDEN

Prof. H. Wilhelmson, Chalmers Univ. of Tech., SWEDEN

Centre Phys. Des Plasmas, Ecole Polytech, SWITZERLAND

Bibliothoek، Inst. Voor Plasma-Fysica, THE NETHERLANDS

Asst. Prof. Dr. S. Cakir, Middle East Tech. Univ., TURKEY

Dr. V.A. Glukhikh,Sci. Res. Inst. Electrophys.I Apparatus, USSR

Dr. D.D. Ryubv, Siberian Branch of Academy of Sa., USSR

Dr. G.A. Elisoov, I.V. Kurchatov Inst, USSR

Librarian, The Ukr.SSA Academy of Sciences, USSR

Dr. L.M. Kovrizhnykh, Inst. of General Physics, USSR

Kemforschungsanlage GmbH, Zentralbibliothek, W. GEAMANY

Bibliothek, Inst. Fur Plasmaforschung, W. GERMANY

Prof. K. Schindier, Ruhr-Universitát Bochum, W. GERMANY

Dr. F. Wagner, (ASDEX), Max-Planck-Institut, W. GERMANY

Librarian, Max-Planck-Institut, W. GERMANY

Prof. R.K. Janev, Inst. of Physics, YUGOSLAVIA 

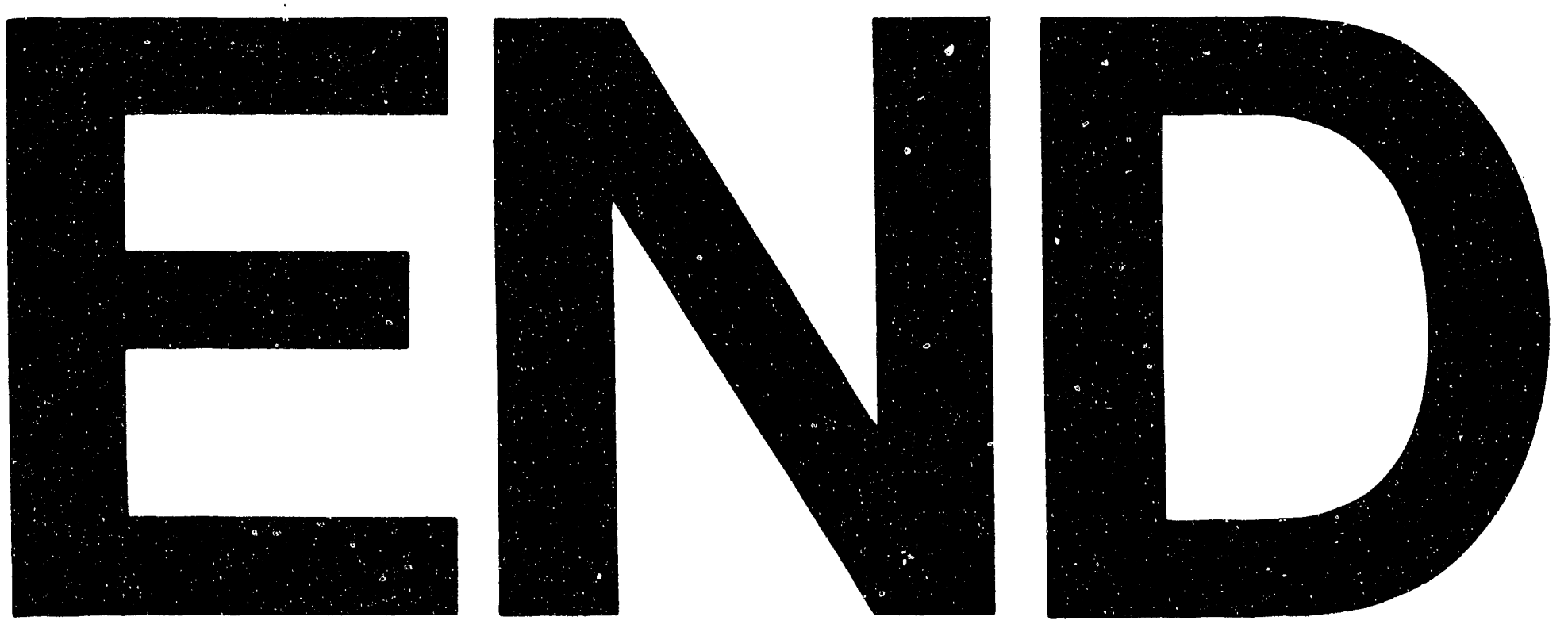

1
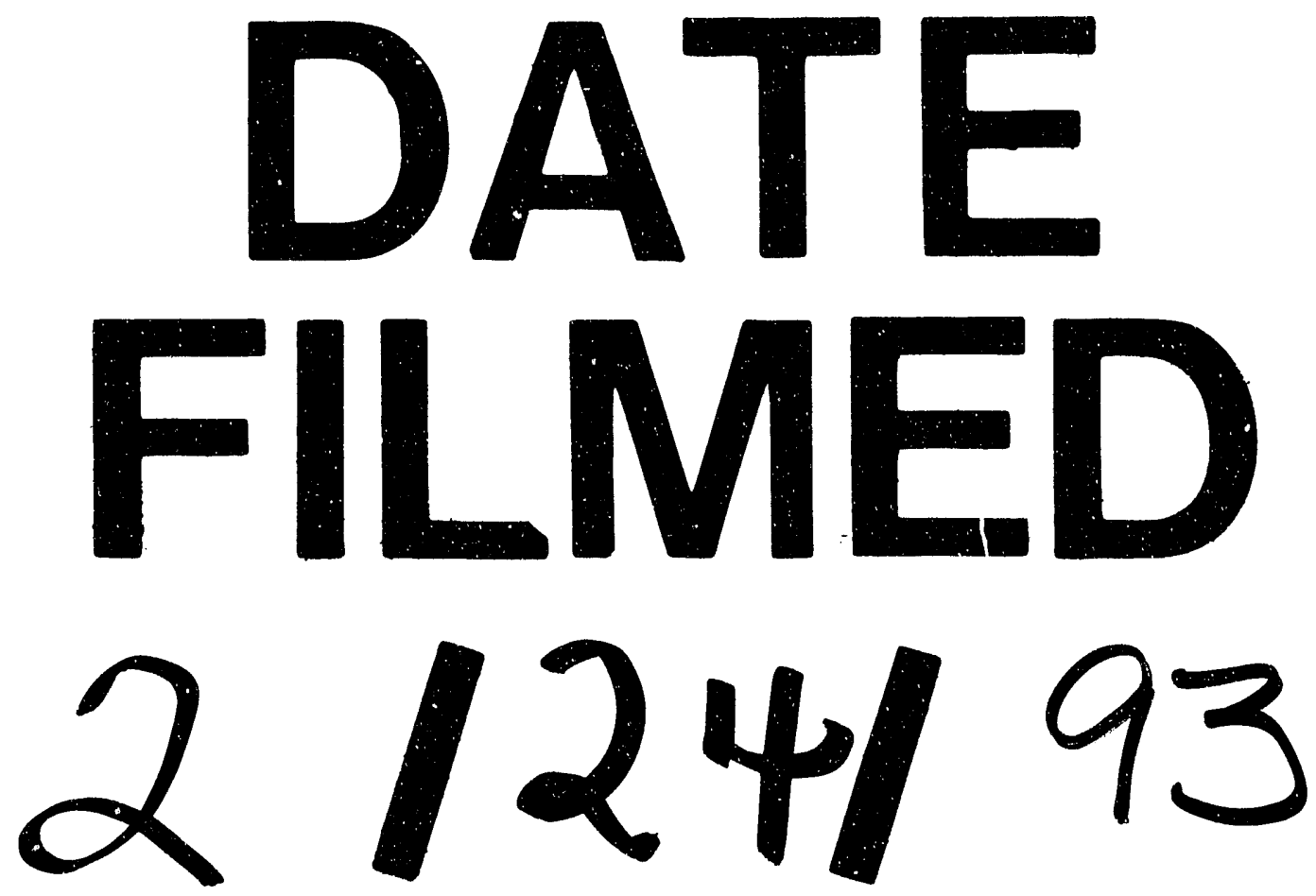
